\title{
Relationship between the stage of digestive tract development in chicks and the effect of viscosity reducing enzymes on fat digestion
}

\author{
Stefania Smulikowska \\ The Kielanowski Institute of Animal Physiology and Nutrition. \\ Polish Academy of Sciences \\ 05 - 110 Jabtonna, Poland
}

\begin{abstract}
Different fats are added to low energy cereal diets for broiler chickens so as to satisfy the energy requirements of the chickens. However, the viscous soluble dictary fibre present in some cereals negatively affects fat digestion and absorption by chickens. Lowering the viscosity of digesta by feed enzyme supplementation of cereal diets enhances fat digestion and absorption. The effect of chicken age and the degree of saturation of the added fat on these processes are discussed.
\end{abstract}

KEY WORDS: viscosity, fat digestion, feed enzymes, chicken

\section{INTRODUCTION}

The successful utilization of microbial enzymes in poultry rations depends upon an understanding of their modes of action and the role they are to perform. Up to now, the most effective enzymes used to improve the nutritional value of cereals containing highly viscous non-starch polysaccharides (NSP) are those with pentosanase and $\beta$-glucanase activity. The beneficial action of these enzymes has been associated with freeing nutrients masked by insoluble cell wall material (Hesselman and Åman, 1986) and with reducing digesta viscosity (Bedford and Classen, 1992). Under practical conditions these enzymes are most effective in the first weeks of life of chickens, with little or no effects seen in adult birds (Brenes et al., 1993) because adult birds digest diets rich in viscous NSPs better than young ones (Smulikowska, 1995). 
The energy density of diets used in the first weeks of life of broiler chickens is very high and reaches $13.4 \mathrm{MJ}$ of metabolizable energy (ME) per $\mathrm{kg}$ of diet. The ME value of cereals containing soluble, viscous non-starch polysaccharides (NSP) is low, so it is necessary to add fat to broiler chicken diets based on such cereals. The lower the ME of the cereal used, the more fat is needed to optimize the energy level of diets. The energy density of laying hen diets reaches only $11.3 \mathrm{MJ} \mathrm{ME} / \mathrm{kg}$ and they rarely need to be supplemented with fat. The relationship between the stage of digestive tract development and the effect of viscosity reducing enzymes on fat digestion is discussed in this paper.

\section{THE ANATOMY AND MOTILITY OF THE DIGESTIVE TRACT OF THE CHICKEN}

The digestive tract of the chicken is relatively shorter and anatomically different from that of mammals. It consist of the beak, the ocsophagus which widens into the crop, the lower oesophagus, proventriculus, gizzard, duodenum, jejunum and ileum. The gizzard connects with the proventriculus by a narrow and short isthmus, and with the duodenum via a narrow pylorus. Pancreatic and bile ducts open into the distal end of the duodenal loop. Regardless of age, the largest parts of the GIT (gastrointestinal tract) involved in digestion are the gizzard and ileum (Table 1), which corresponds with their importance in the digestive process. The feed which enters the gizzard is degraded mechanically by grinding and vigorously mixing. The gizzard movements are pendular; contractions are rapid, of the order of 2 to 3 per min, followed by contractions of the proventriculus. Due to

TABLE 1

Mass (g) and relative share of parts of digestive tract (DT, \%)* in male broiler chickens and adult hens (after Smulikowska, 1998)

\begin{tabular}{|c|c|c|c|c|c|c|}
\hline \multirow{4}{*}{$\begin{array}{l}\text { Item } \\
\text { Live body weight, } g \\
\text { Digestive tract, } g \\
\text { Parts of DT }\end{array}$} & \multicolumn{2}{|c|}{$\begin{array}{c}\text { Male broilers } \\
\text { 9-days-old }\end{array}$} & \multicolumn{2}{|c|}{$\begin{array}{l}\text { Male broilers } \\
24 \text {-days-old }\end{array}$} & \multicolumn{2}{|c|}{$\begin{array}{l}\text { Laying hens } \\
48 \text {-weck-old }\end{array}$} \\
\hline & \multicolumn{2}{|c|}{200.7} & \multicolumn{2}{|c|}{1017.0} & \multicolumn{2}{|c|}{1886.7} \\
\hline & \multicolumn{2}{|c|}{19.8} & \multicolumn{2}{|c|}{61.6} & \multicolumn{2}{|c|}{93.0} \\
\hline & $g$ & $\%$ DT & g & $\%$ DT & $\mathrm{g}$ & $\%$ DT \\
\hline crop & 1.2 & 6.2 & 4.2 & 6.8 & 6.7 & 7.2 \\
\hline proventriculus & 2.1 & 10.7 & 6.3 & 10.3 & 7.7 & 8.3 \\
\hline gizzard & 7.3 & 36.6 & 16.6 & 27.0 & 32.0 & 34.4 \\
\hline duodenum & 2.1 & 10.6 & 8.3 & 13.4 & 9.5 & 10.2 \\
\hline ileum & 7.1 & 35.9 & 26.2 & 42.5 & 37.1 & 39.9 \\
\hline
\end{tabular}

* sum of empty crop, proventriculus, gizzard, duodenum, ileum 
these contractions, the digesta is shuttled between the proventriculus and gizzard, and liquid digesta is pushed through the pylorus into the duodenum. In the duodenum, peristalsis is followed by antiperistalsis. In the turkey, intestinal refluxes occur 2 or 3 times per h, involving the entire duodenum and the upper ileum in one or two antiperistaltic contractions (Duke, 1982, 1992). In the chick this process is continuous, enabling penetration of the gizzard by duodenal contents during the contractile period of the gizzard. This motility pattern is unique to birds and enables reverse passage of intestinal digesta containing pancreatic and intestinal juice, and bile into the gizzard and proventriculus (Sklan et al., 1978). The presence of bile salts in the gizzard enables fat emulsification, which is necessary for the further stages of digestion and absorption in the duodenum and jejunum. The shuttling of digesta between the gizzard and duodenum increases the time the feed is exposed to digestive enzymes and favours its absorption in the upper parts of the small intestine.

\section{DIGESTION OF FAT IN POULTRY}

Fat digestion in chicks is a complex process. Ingested lipids must first be emulsified in the presence of conjugated bile salts. Fairly large $(5000 \AA)$ droplets of emulsion are subjected to the hydrolytic action of pancreatic lipase in the presence of colipase and pancreatic phospholipase A2. The products of lipolysis - unsaturated long chain fatty acids, medium chain free fatty acids, monoglycerides and phospholipids, spontaneously form mixed micelles with conjugated bile salts ( 30 to $100 \AA$ ). The hydrophobic cores of these micelles are able to solubilize long chain saturated fatty acids, fat soluble vitamins and cholesteryl esters. Micelles, dispersed in the aqueous medium of the intestinal lumen, are transported to the mucosal surface and pass through the brush border membrane, leaving bile salts in the gut lumen (Scott at al., 1982; Krogdahl, 1985). The effectiveness of utilization of dietary fat by chickens depends on its degree of saturation. Fats rich in unsaturated fatty acids are better digested and absorbed than saturated fats. Tallow, due to the specific arrangement of saturated and unsaturated fatty acid on the glycerol moiety of the triglyceride molecule (a high proportion of palmitic and stearic acid is distributed throughout positions 1 - and 3- of the triglyceride) is poorly digested and absorbed by poultry. Both palmitic and stearic fatty acids are nonpolar and cannot form mixed micelles spontaneously, but can be solubilized by such micelles formed from unsaturated fatty acids and conjugated bile salts. Tallow is better absorbed in the presence of vegetable oil as there are more mixed micelles in the digesta (Wiseman, 1990). The main site of lipid absorption in fowls is the duodenum and jejunum, while the bile salts are absorbed in the jejunum and ileum (Scott et al., 1982; Johnson, 1992). 
In newly hatched chicks the intestinal system is anatomically complete and its capacity to digest starch and fats is essentially complete by day 4 , whereas $\mathrm{N}$ digestion increases from $70-80 \%$ on day 4 to $90 \%$ on day $10-14$ (Noy and Sklan, 1995; Uni et al., 1995). The broiler chick has a reserve of bile acids in the yolk sac after hatching, however, the concentration of bile acids in the gastrointestinal tract is relatively low in the first weeks of life (Inarrea et al., 1989).

\section{PHYSIOLOGICAL EFFECTS OF THE VISCOSITY OF WATER SOLUBLE NSPS ON FAT DIGESTION IN BIRDS}

The viscosity of digesta depends on the structure and size of soluble NSP molecules ingested by birds, as well as on their concentration (Bedford and Classen, 1992; Annison, 1995). From among the cereals the most viscous are arabinoxylans and $\beta$-glucans present in rye, barley, oats and some varieties of wheat. Increasing substitution of rye by wheat (Table 2) caused a substantial decrease in fat digestibility both in the experiments of Antoniou and Marquardt (1982) and Ward and Marquardt (1983).

Knowledge about how the physicochemical properties of NSPs might affect fat digestion in poultry is limited. It has been suggested that high digesta viscosity

TABLE 2

Effect of rye level and enzyme supplementation on apparent fat digestibility (AFD), AME $\mathrm{N}_{\mathrm{N}}$ and metabolizability of energy in 4-week old broiler chickens (after Smulikowska and Mieczkowska, 1996)

\begin{tabular}{ccccc}
\hline Rye level, \% & $\begin{array}{c}\text { Enzyme } \\
-+\end{array}$ & $\begin{array}{c}\mathrm{AFD} \\
\%\end{array}$ & $\begin{array}{c}\mathrm{AME}_{\mathrm{N}} \mathrm{MJ} / \mathrm{kg} \\
\mathrm{DM}\end{array}$ & $\begin{array}{c}\mathrm{AME}_{\mathrm{N}} / \mathrm{GE} \\
\%\end{array}$ \\
\hline 0 & - & 91.5 & 14.58 & 74.8 \\
0 & + & 90.6 & 14.56 & 74.7 \\
15 & - & 83.6 & 13.73 & 70.6 \\
15 & + & 91.5 & 14.00 & 72.9 \\
30 & - & 82.8 & 13.26 & 69.0 \\
30 & + & 87.5 & 13.93 & 72.6 \\
45 & - & 74.7 & 12.24 & 63.6 \\
45 & + & 83.3 & 13.54 & 70.9 \\
Pooled SEM & - & 1.10 & 0.12 & 0.63 \\
Source of variation & & & & \\
rye & & 0.001 & 0.001 & 0.001 \\
enzyme & & 0.001 & 0.001 & 0.001 \\
rye x enzyme & & 0.001 & 0.001 & 0.001 \\
\hline
\end{tabular}

- diet containing $8.5 \%$ added mixed fat (soya oil + lard $1: 1$ ) 
associated with ingestion of soluble viscous NSP slows proper reflux of digesta and makes diffusion and convective transport of droplets of emulsion, fatty acids, mixed micelles, bile salts and lipase within the gastrointestinal contents more difficult, reducing transport of micelles to the mucosal surface. Molecules of NSP in solution can present charged, weakly hydrophobic and weakly hydrophilic surfaces. They may associate with surfaces of food particles, lipid micelles or the glycocalyx surface of the gut (Johnson, 1992; Annison, 1995). Viscous polysaccharides might also directly complex with digestive enzymes and reduce their activity (Ikeda and Kusano, 1983). It has been shown that gel-forming gums and pectins give rise to an increase in the thickness of the unstirred water layer, which is adjacent to the intestinal mucosa (Johnson and Gee, 1981, 1986 after Johnson, 1992), which in turn may increase its resistance to the transport of nutrients. The absorption of fatty acids may be impaired by gelling agents if the effective surface of the microvilli or the function of the fatty acid binding protein in the mucosal membrane are diminished (Smits and Annison, 1996).

It was demonstrated (Rakowska et al., 1993) that in very young chicks fed a diet based on rye, with a very high content of soluble dietary fibre, resulted in severe damage of intestinal villi and the mucous layer of the duodenum and small intestine. This was due to the proliferation of detrimental microflora, since the addition of an antibiotic protected the intestinal walls. Changes in the morphology of the villi and microvilli may also affect fatty acid absorption. With a rise in the concentration of soluble, viscous NSP in digesta, more undigested organic matter reaches the ileum, which in turn promotes the proliferation of detrimental microflora, which can deconjugate bile acids (Campbell et al., 1983a, b). Binding of bile acids by gel-forming soluble dietary fibres, as well as excessive bacterial bile acid deconjugation, may lead in turn to poor fat solubilization, as free bile acids are not active in micelle formation (Nagengast, 1992). Campbell et al. (1983a, b) demonstrated that the addition of sodium taurocholate to the rye-based diet substantially improved the digestibility of lipids.

Finally it is possible that endogenous lipid losses may increase due to binding of bile by viscous NSPs. Contrary to that of mammals, the bile of broiler chickens contains a large amount of triacylglycerols and cholesteryl esters (Noble and Conner, 1984; Noble et al., 1988, after Smits and Annison, 1996). In our own experiment (Smulikowska, 1998) the apparent fat digestibility of 10-day old broiler chickens fed rye averaged only $0.6 \%$, and in a few birds negative values were obtained, which points to endogenous lipid losses (Table 3 ).

Under experimental (Tables 3 and 4) and practical (Table 5) conditions, supplementation of broiler chicken diets containing cereals rich in soluble viscous NSP with feed enzymes lowers digesta viscosity and increases digestion and absorption of nutrients, which improves the performance of the birds. 
TABLE 3

Effect of age of the chicks on AFD, organic matter retention (OMR) and $\mathrm{AME}_{\mathrm{N}}$ of rye, triticale and wheat (after Smulikowska, 1998)

\begin{tabular}{|c|c|c|c|c|}
\hline Cereal & Age of birds* & $\begin{array}{c}\text { AFD } \\
\% \\
\end{array}$ & $\begin{array}{c}\text { OMR } \\
\% \\
\end{array}$ & $\begin{array}{c}\mathrm{AME}_{\mathrm{N}} \mathrm{MJ} / \mathrm{kg} \\
\mathrm{DM}\end{array}$ \\
\hline \multirow[t]{2}{*}{ Rye } & young & 0.6 & 61.7 & 11.0 \\
\hline & adult & 74.8 & 76.4 & 14.9 \\
\hline \multirow[t]{2}{*}{ Triticale } & young & 46.8 & 75.5 & 14.4 \\
\hline & adult & 78.3 & 78.7 & 14.3 \\
\hline \multirow[t]{2}{*}{ Wheat } & young & 60.3 & 73.2 & 13.7 \\
\hline & adult & 78.9 & 80.4 & 15.1 \\
\hline Pooled SEM & & 2.4 & 1.4 & 0.2 \\
\hline Source of variation & & \multicolumn{2}{|c|}{ Probability } & \\
\hline cereal & & 0.01 & 0.01 & 0.01 \\
\hline age of bird & & 0.01 & 0.01 & 0.01 \\
\hline cereal $x$ age & & 0.01 & 0.01 & 0.01 \\
\hline
\end{tabular}

* young 10-day-old broiler cockerels; adult 45-week-old White Leghorn cockerels

TABLE 4

Effect of fat source and enzyme supplementation on AFD, AME ${ }_{\mathrm{N}}$, metabolizability of energy, and viscosity of excreta and digesta (in cP) (after Smulikowska and Mieczkowska, 1996)

\begin{tabular}{|c|c|c|c|c|c|c|}
\hline Fat source & $\begin{array}{c}\text { Enzyme } \\
-+\end{array}$ & $\begin{array}{c}\text { AFD } \\
\%\end{array}$ & $\begin{array}{c}\mathrm{AME}_{\mathrm{N}} \\
\mathrm{MJ} / \mathrm{kg} \mathrm{DM}\end{array}$ & $\begin{array}{c}\mathrm{AME}_{\mathrm{N}} / \mathrm{GE} \\
\% \\
\end{array}$ & $\begin{array}{l}\text { Viscos } \\
\text { excreta }\end{array}$ & $\begin{array}{l}\text { ity, cP } \\
\text { ilcal digesta }\end{array}$ \\
\hline Soya oil & - & 75.9 & 13.53 & 64.9 & 50.3 & 49.8 \\
\hline Lard & - & 66.4 & 12.86 & 64.0 & 130.4 & 46.2 \\
\hline Tallow & - & 45.5 & 12.25 & 58.8 & 287.7 & 30.7 \\
\hline Mixed fat* & - & 61.7 & 13.02 & 64.3 & 92.6 & 41.2 \\
\hline Soya oil & + & 84.8 & 14.69 & 71.3 & 29.0 & 16.5 \\
\hline Lard & + & 77.7 & 13.80 & 68.3 & 30.8 & 17.9 \\
\hline Tallow & + & 63.1 & 13.90 & 67.6 & 27.4 & 20.5 \\
\hline Mixed fat* & + & 73.9 & 14.76 & 70.6 & 23.1 & 16.4 \\
\hline Pooled SEM & & 1.8 & 0.20 & 1.0 & 27.7 & 2.7 \\
\hline Source of variation & \multicolumn{6}{|c|}{ Probability } \\
\hline fat & & 0.001 & 0.001 & 0.001 & 0.001 & 0.05 \\
\hline enzyme & & 0.001 & 0.001 & 0.001 & 0.001 & 0.01 \\
\hline fat $x$ enzyme & & NS & NS & NS & 0.05 & 0.001 \\
\hline
\end{tabular}

* soya oil and tallow in proportion $1: 1$ 
TABLE 5

Effect of rape seed oil (RO) and feed enzyme supplementation on body weight (BW, g) and feed conversion ratio (FCR, g/g) of 6-week-old broiler chickens fed cereal-based isoprotein diets (after Rutkowski, 1996)

\begin{tabular}{lcccccc}
\hline Cereal in diet & \multicolumn{3}{c}{ Unsupplemented } & \multicolumn{2}{c}{$\begin{array}{c}\text { RO (up to 13 MJ } \\
\text { EM/kg diet) }\end{array}$} & \multicolumn{2}{c}{ +RO + feed enzyme } \\
& BW & FCR & BW & FCR & BW & FCR \\
\hline Maize & 1447 & 2.07 & 1604 & 2.05 & 1596 & 1.93 \\
Wheat & 1261 & 2.33 & 1555 & 2.14 & 1599 & 1.91 \\
Triticale & 1352 & 2.37 & 1562 & 2.06 & 1608 & 1.92 \\
Barley & 968 & 2.72 & 1443 & 2.24 & 1522 & 2.00 \\
Oat & 839 & 2.80 & 1169 & 2.06 & 1349 & 1.94 \\
Rye & 867 & 2.85 & 1072 & 2.70 & 1331 & 2.38 \\
\hline
\end{tabular}

\section{INTERACTION BETWEEN VISCOSITY AND DEGREE OF FAT SATURATION}

Tallow-fortified diets have often been used to prove a beneficial action of enzyme supplementation on the $\mathrm{AME}_{\mathrm{N}}$ value of rye-based diets (Fengler and Marquardt, 1988; Friesen et al., 1992; Marquardt et al., 1994). Choct and Annison (1992 a,b) reported that the depression of lipid digestibility was proportional to the content of wheat pentosans in the diet, - digestibility of saturated was more affected than of unsaturated fatty acids. Supplementation of rye-containing diets with saturated fats causes a substantial elevation in the viscosity of ileal digesta and excreta. Dänicke et al. (1995) reported that in 28-day-old birds fed a rye-tallow diet the viscosity in the jejunum was $100 \%$, but in the ileum it was $240 \%$ higher than in birds fed a rye-soya oil diet. The effect of fat saturation on ileal viscosity was not confirmed in our experiment (Smulikowska and Mieczkowska, 1996) but the droppings of chicks fed a rye-tallow diet were $470 \%$ more viscous than of birds fed a rye-soya oil diet (Table 4). The presence of substantial amounts of undigested fats, connected with viscous NSP could have delayed the movement of digesta. Under these conditions, more insoluble NSP may have became solubilized in the last parts of digestive tract due to the action of microflora, adding to the viscosity and stickiness of excreta. The viscosity of digesta and excreta after enzyme supplementation diminished significantly and did not depend on the source of added fat.

The difference between the digestibility of soya oil and lard, tallow and mixed fat in unsupplemented wheat-rye diets reached 10,30 and 14 percent, respectively. Reduction of digesta viscosity due to supplementation of diets with feed enzyme improved fat digestibility by $21 \%$ on average, and the difference between the digestibility of soya oil and other fats diminished to 7,22 and 11 percent (Table 4). 
The increase in fat digestibility was correlated with better metabolizability of energy and higher $\mathrm{AME}_{\mathrm{N}}$ valuc of the diets, as found in the experiments of Dänicke et al. (1995) and Schutte et al. (1995).

\section{THE RELATIONSHIP BETWEEN THE AGE OF THE BIRDS AND THE EFFECT OF VISCOSITY ON FAT DIGESTION}

The effect of viscosity on fat digestion is not so detrimental in adult birds, as diets containing $65 \%$ of wheat, barley, oats or rye supplemented with tallow did not negatively affect the laying rate, and enzyme supplementation did not have a positive effect on laying performance (Brenes et al., 1993). The absolute mass of GIT tissues increases when birds mature, even if it decreases relative to live body weight (Table 1). However, in the very young chick, the weight, hence the thickness of muscular walls and the diameter of the GIT, is smaller than in adult birds. Increases in the thickness of the unstirred water layer due to NSP action may further diminish the diameter of the intestines. It is obvious that the strength needed to push digesta through the intestinal tract increases with rising viscosity, and decreases with increasing GIT diameter. The muscular walls of the GIT in young birds are relatively thin, and not strong enough to effectively relocate viscous digesta. The high viscosity of intestinal contents, due to feeding rye or low quality wheat, disturbs the proper flow of digesta to and from the gizzard and often results in dilation of the proventriculus and gizzard in broiler chicks and atrophy of the isthmus, with the dilation reaching the crop in severe cases (Scott, 1993; Smulikowska, 1998). A dilated gizzard does not work effectively, which may disturb the fat cmulsification necessary for digestion to proceed. A decrease in digesta viscosity enabling proper flow of digesta may have a positive effect on fat digestion. This is not so important in adult birds, as their small intestine is wider and the muscular layer of the GIT is sufficiently strong for even viscous digesta to be properly mixed and relocated. Also, the bacterial flora of adult birds is established and does not change as dramatically in the presence of viscous NSPs. Due to this, apparent fat digestion in adult birds is not as dependant on the presence of soluble viscous NSP as in young birds (Table 3 ) and the effect of enzyme supplementation is less pronounced.

\section{CONCLUSIONS}

It may be concluded that the presence of viscous NSP, the degree of saturation of added fat, and the age of the birds greatly affect utilization of fat in poultry. Supplementation with enzyme preparations containing xylanase and $\beta$-glucanase 
is particularly advisable if diets prepared for very young chickens contain viscous NSP and are fortified with animal fat, since it may greatly enhance the retention of fat and metabolizability of energy. The effect is associated with a reduction in the viscosity of digesta and excreta. The effect of enzyme supplementation on fat digestion is negligible in adult birds.

\section{REFERENCES}

Annison G., 1995. Feed enzymes - the science, future developments and practical aspects in feed formulation. Proceedings of $10 \mathrm{th}$ European Symposium on Poultry Nutrition, Antalya, Turkey, pp.193-201

Antoniou T.C., Marquardt R.R., 1982. Utilization of rye diets by chicks as affected by lipid type and level and penicillin supplementation. Poultry Sci. 61, 107-116

Bedford M.R., Classen H.L., 1992. Reduction of intestinal viscosity through manipulation of dictary rye and pentosanase concentration is effected through changes in the carbohydrate composition of the intestinal aqueous phase and results in improved growth rate and food conversion efficiency of broiler chicks. J. Nutr. 122, 560-569

Brenes A., Guenter W., Marquardt R.R., Rotter B.A., 1993. Effect of $\beta$-glucanase/pentosanase enzyme supplementation on the performance of chickens and laying hens fed wheat, barley, naked oats and rye diets. Can. J. Anim. Sci. 73, 941-951

Camphell G.L., Campbell L.D., Classen H.L., 1983a. Utilisation of rye by chickens: effect of microbial status, diet gamma irradiation and sodium taurocholate supplementation. Brit. Poultry Sci. 24, 191-203

Campbcll G.L., Classen H.L., Goldsmith K.A., 1983b. Effect of fat retention on the rachitogenic effect of rye fed to broiler chicks. Poultry Sci. 62, 2218-2223

Choct M., Annison G., 1992a. The inhibition of nutrient digestion by wheat pentosans. Brit. J. Nutr. 67, 123-132

Choct M., Annison G., 1992b. Anti-nutritive effect of wheat pentosans in broiler chickens: Role of viscosity and gut microflora. Brit. Poultry Sci. 33, 821-834

Dänicke S., Simon O., Jeroch H., Bedford M., 1995. Effect of fat source and xylanase supplementation on the performance and intestinal viscosity in rye fed birds. Proceedings of 2 nd European Symposium on Feed Enzymes, Noordwijkerhout, The Netherlands, pp. 102-106

Duke G.E., 1982. Gastrointestinal motility and its regulation. Poultry Sci. 61, 1245-1256

Duke G.E., 1992. Recent studies on regulation of gastric motility in turkeys. Poultry Sci. 71, 1-8

Fengler A.I., Marquardt R.R., 1988. Water-soluble pentosans from rye: Il. Effects on rate of dialysis and on the retention of nutrients by the chick. Cereal. Chem. 65, 298-302

Friesen O.D., Guenter W., Marquardt R.R., Rotter B.A., 1992. The effect of enzyme supplementation on the apparent metabolizable energy and nutrient digestibilities of wheat, barley, oats, and rye for the young broiler chick. Poultry Sci. 71, 1710-1721

Hesselman K., Åman P., 1986. The effect of beta-glucanase on the utilization of starch by broiler chickens fed low and high viscous barley. Anim. Feed Sci. Technol. 15, 83-93

Ikeeda K., Kusano T., 1983. In vitro inhibition of digestive enzymes by indigestible polysaccharides. Cereal Chem. 60, 260-263

Inarrea P., Simon M., Manzano M., Palacios J., 1989. Changes in the concentration and composition of bilary and serum bile acids in young domestic fowl. Brit. Poultry Sci. 30, 353-359 
Johnson I.T., 1992. The influence of dietary fibre on lipid digestion and absorption. In: T.F. Schweizer, C. Edwards (Editors). Dietary fibre - A Component of food - Nutritional function in health and disease. Springer-Verlag, London: ILSI Europe, pp. 167-180

Krogdahl A., 1985. Digestion and absorption of lipids in poultry. J. Nutr. 115, 675-685

Marquardt R.R., Boros D., Guenter W., Crow G., 1994. The nutritive value of barley, rye, wheat and corn for young chicks as affected by use of a Trichoderma reesei enzyme preparation. Anim. Feed Sci. Technol, 45, 363-378

Nagengast F.M., 1992. Dietary fibre and bile acid metabolism. In: T.F. Schweizer, C. Edwards (Editors). Dictary fibre - A Component of food - Nutritional function in health and disease. Springer-Verlag London: ILSI Europe, pp. 217-231

Noy Y., Sklan D., 1995. Digestion and absorption in the young chick. Poultry Sci. 74, 366-373

Pettersson D., Åman P., 1988. Effects of enzyme supplementation of diets based on wheat, rye or triticalc on their productive value for broiler chickens. Anim. Feed Sci. Technol. 20, 313-324

Rakowska M., Rek-Ciepły B., Sot A., Lipińska E., Kubiński T., Barcz I., Afanasjew B., 1993. The effect of rye, probiotics and nisine on faecal flora and histology of the small intestine in chicks. J. Anim. Feed Sci. 2,73-81

Rutkowski A., 1996. Nutritive value of grains for broiler chicken (in Polish). Rocz. Akad. Rol. Poznań, Poland, No. 267

Schutte J. B., de Jong J., Langhout D.J., 1995. Effect of a xylanase enzyme supplementation to wheat-based diets in broiler chicks in relation to dietary factors. Proceedings of 2 nd European Symposium on Feed Enzymes, Noordwijkerhout, The Netherlands, pp. 95-101

Scott T. A., 1993. Cultivar and wheat origin influence AME level and incidence of dilated proventriculi and gizzard of broiler chicks. Poultry Sci. 72, Suppl.1, 128

Scott M.L., Nesheim M.C., Young R.J., 1982. Nutrition of the chicken. 3rd Edition, Publ. by M. L. Scott and Ass. Ithaca, New York

Sklan D., Schachaf B., Baron J., Hurwitz S., 1978. Retrograde movement of digesta in the duodenum of the chick: extent frequency and nutritional implications. J. Nutr. 108, 1485-1490

Smits C. H. M., Annison G., 1996. Non-starch plant polysaccharides in broiler nutrition - towards a physiologically valid approach to their determination. World's Poultry Sci. J. 52, 203-221

Smulikowska S., 1995. Effect of age and enzyme supplementation on metabolizable energy of rye, triticale and wheat for poultry. Proceedings of 10th European Symposium on Poultry Nutrition, Antalya, Turkey, pp. 258-259

Smulikowska S., 1998. Nutritive value of rye, triticale and wheat for poultry (in Polish). The Kielanowski Institute of Animal Physiology and Nutrition, Polish Academy of Sciences, Jabłonna, Poland, pp. 159

Smulikowska S., Mieczkowska A., 1996. Effect of rye level, fat source and enzyme supplementation on fat utilization, diet metabolizable energy, intestinal viscosity and performance of broiler chickens. J. Anim. Feed Sci. 5, 379-393

Uni Z., Noy Y., Sklan D., 1995. Posthach changes in morphology and function of the small intestines in heavy- and light-strain chicks. Poultry Sci. 74, 1622-1629

Wiseman J., 1990. Variability in the nutritive value of fats for non-ruminants. In: J. Wiseman, D. J. A. Cole (Editors). Feedstuff evaluation. Butterworths, London-Boston-Singapore-Sydney-Toronto-Wcllington, pp. 215-234

Ward A.T., Marquardt R.R., 1983. The effect of saturation, chain length of pure triglycerides, and age of bird on the utilization of rye diets. Poultry Sci. 62, I054-1062 